\title{
Examination of Derecho Environments Using Proximity Soundings
}

\author{
JEFFRY S. EVANS \\ Storm Prediction Center, Norman, Oklahoma \\ Charles A. Doswell III \\ National Severe Storms Laboratory, Norman, Oklahoma \\ (Manuscript received 9 November 1999, in final form 25 January 2001)
}

\section{ABSTRACT}

\begin{abstract}
Observed upper air soundings that occurred within $2 \mathrm{~h}$ and $167 \mathrm{~km}$ of derechos were collected and analyzed to document atmospheric stability and wind shear conditions associated with long-lived convective windstorms. Sixty-seven derechos, accompanied by 113 proximity soundings, were identified during the years $1983-93$. Owing to the large variability of the synoptic-scale environments associated with derechos, each derecho was further divided into categories based on the strength of synoptic-scale forcing associated with each event.

Derechos are shown to develop and persist in a wide range of shear and instability conditions. Although this range of shear and instability narrows when derechos are grouped by synoptic-scale forcing strength, considerable variation of values remains, primarily with the shear. These results suggest that ambient shear and instability values alone are not sufficient to distinguish derecho environments from those associated with nonsevere mesoscale convective system (MCS) environments. Though the ground-relative (ambient) shear values vary, more consistency is found in the system-relative winds. It is found that midlevel system-relative winds are consistently weak, while low-level system-relative inflow is strong. This is especially valid for events associated with weak synoptic-scale forcing. Fast forward propagation is associated with weak system-relative midlevel winds, which may in turn be associated with outflow-dominated storms having strong cold pools at the ground. In addition, a comparison between weak forcing derecho and nonderecho MCSs suggests that it is the strength of the mean flow, and its possible effects on speed of movement, that enhance the potential for sustained severe wind gusts at the surface, given similar thermodynamic environments.

These results indicate that there is a larger range of shear and instability environments associated with derechos than has been suggested by some observational studies and numerical cloud simulations. In addition, little correlation is evident in operational observations between events with strong cold pools and those with correspondingly strong low-level $(0-2 / 0-3 \mathrm{~km})$ ambient shear. Owing to the large variance of convective available potential energy (CAPE)/shear values found in this observational study, forecasters should be aware of the potential for derecho formation within environments with weaker shear than suggested by numerical simulations. This is especially true in the absence of a deep, progressive midtropospheric trough and an associated surface cold front. When synoptic-scale forcing is strong, derechos can develop and persist within environments with almost no CAPE evident on nearby upper air soundings.
\end{abstract}

\section{Introduction}

Convective windstorms have long been discussed in the literature, and are responsible for considerable damage, and numerous casualties across the United States each year. Though the convection responsible for damaging surface winds can vary in size from a single thunderstorm to a large convective complex, long-lived, rapidly moving squall lines account for the most severe and widespread convectively induced wind damage. Fujita (1978) introduced the term "bow echo" in the late 1970 s to describe bow-shaped radar reflectivity signa-

Corresponding author address: Jeff Evans, Storm Prediction Center, 1313 Halley CR, Norman, OK 73069.

E-mail: Jeffry.Evans@noaa.gov tures associated with the majority of these windstorms. Observations have revealed that these radar echo structures can vary in size from a few tens of kilometers to more than $200 \mathrm{~km}$ in length, and can last for $18 \mathrm{~h}$ or more in extreme cases.

Nontornadic damaging winds associated with deep convection are almost always generated by outflow from the base of a downdraft (Johns and Doswell 1992). Negative buoyancy, attributable to the effects of evaporative cooling when precipitation falls through a layer of unsaturated air, is an important contributor to the development and maintenance of strong downdrafts (e.g., Browning and Ludlam 1962; Hookings 1965). Once this convectively cooled air reaches the surface, it forms a "pool" of cold air that can build into a "mesohigh" in the pressure field as the convection becomes more or- 
ganized and intense. It is an intense mesohigh that Hamilton (1970) attributes to the "bulging echo" of a line echo wave pattern (as identified by Nolen 1959), and which Fujita (1978) attributes to bow echoes. Fujita (1978) and many other recent studies (e.g., Przybylinski and Gery 1983; Przybylinski 1995) emphasize the association of bow echoes with long swaths of damaging straight-line winds. Johns and Hirt (1987, hereafter JH87) conducted an extensive study of convective windstorms occurring during the warm season (May-Aug) calling the long-lived, widespread cases derechos, after Hinrichs (1888). Examination of radar-echo configurations associated with these events strongly suggests that derechos are associated with bow echoes or bowing segments of varying scales within a larger squall line (Przybylinski and DeCaire 1985; JH87).

JH87 found that derecho environments were characterized by copious moisture at low levels and extreme instability (average lifted index of -9 ), though lesser instability accompanied the "strong" 500-mb shortwave troughs in their dataset. These findings were supported by Johns et al. (1990), who examined 14 very intense derechos that occurred during the months of June and July. They found that convective available potential energy (CAPE) values generally were greater than $2400 \mathrm{~J} \mathrm{~kg}^{-1}$ near the genesis region of the strong derecho cases, though CAPE increased to an average maximum of $4500 \mathrm{~J} \mathrm{~kg}^{-1}$ as the convective system moved eastward. Average surface to $700 \mathrm{mb}$ (corresponding roughly to $0-3 \mathrm{~km}$ ) shear vector magnitudes were found to be near $15 \mathrm{~m} \mathrm{~s}^{-1}$, with surface to 500 $\mathrm{mb}$ (corresponding roughly to $0-6 \mathrm{~km}$ ) shear vector magnitudes around $20 \mathrm{~m} \mathrm{~s}^{-1}$.

By examining synoptic-scale meteorological aspects of a large number of derechos, JH87 and Johns et al. (1990) found that long-lived derechos were associated with rather well-defined parameter patterns. However, both studies sampled events only during the warm season. This bias was addressed by Johns (1993), who stated that combinations of wind speeds in the lower-tomiddle troposphere and instability appeared to vary widely when considering all bow echo situations when damaging winds occur. Johns (1993) emphasized that derechos can occur any time of the year when associated with strong extratropical cyclones.

A number of numerical cloud modeling studies (Rotunno et al. 1988, hereafter referred to as RKW; Weisman et al. 1988; Weisman 1992, 1993) have sought to simulate long-lived severe squall line development. These studies explore the storm-scale evolution in the development and maintenance of long-lived squall lines or bow echoes, with an emphasis on the effects of environmental shear. Results from Weisman's (1992, 1993) simulations indicate conditions become "optimum" for sustained bow echo development when vertical wind shear of $20 \mathrm{~m} \mathrm{~s}^{-1}$ or greater occurs in the lowest $2.5-5 \mathrm{~km}$ above ground level (AGL). Note that optimality in RKW and Weisman $(1992,1993)$ is de- fined with respect to domain-averaged precipitation and does not imply that such environments are optimum with respect to the strength of their surface winds or with the duration of the squall line. Weisman (1993) indicates that significant, long-lived bow echoes develop in the simulations when the cold pool circulation becomes stronger than the low-level shear, allowing the system to develop an upshear-tilted structure. He also suggests that strong vertical shear and correspondingly high values of CAPE are needed to support the enhancement of certain mesoscale circulations (such as an elevated rearinflow jet and strong bookend vorticies) within convective systems, which "negate the dominant circulation of the cold pool, re-establishing deep, forced lifting along the leading edge of the system.'

Given the differences of CAPE and shear between operational observations and the results of the cited numerical simulations, and the tendency in many studies for a bias toward warm season events, Johns (1993) highlighted the need to examine in more detail the lower-to-middle-tropospheric wind structure and instability associated with a large number of derechos occurring year-round. Our study is an attempt to carry out this suggestion and improve the ability to forecast long-lived bow echoes by examining proximity soundings. Although it is recognized that proximity soundings have some potential shortcomings (discussed in Brooks et al. 1994a), we have identified proximity soundings associated with a large number of derechos to refine our knowledge of the range of environments conducive to these long-lived convective wind storms. We then compare these environments with the results of the numerical simulation experiments.

\section{Methodology}

Storm Data publications were examined for the years 1988-93 to identify derechos occurring within the contiguous United States. Derechos were inferred from convective wind damage patterns in a way similar to that done in JH87. To be included as a derecho, each event must

1) exhibit a progressive path of severe wind gusts $\geq 25$ $\mathrm{m} \mathrm{s}^{-1}(50 \mathrm{kt})$ or wind damage with a major axis $\geq 400 \mathrm{~km}$ (240 $\mathrm{n} \mathrm{mi}$ ) in length and a minor axis $\geq 74$ $\mathrm{km}(40 \mathrm{n} \mathrm{mi})$ in width,

2) exhibit a near-continuous damage path with no more than $2 \mathrm{~h}$ or $167 \mathrm{~km}$ (100 mi) between successive concentrations of severe wind reports,

3) exhibit a linear signature on archived radar charts, and

4) not be associated with tropical storms or hurricanes.

Cases identified for the years 1988-93 were supplemented by those cases used by Johns et al. (1990) that encompassed the summer months from 1983 through 1987. From this set of candidate events, each case then was examined for proximity soundings. To qualify as a 
proximity sounding, the observed sounding must have been taken within both $2 \mathrm{~h}$ and $167 \mathrm{~km}(100 \mathrm{mi})$ of the wind damage path, or the bow echo location as shown by the radar charts. Further, the soundings must have been uncontaminated by the convection, and located directly within or near the ensuing damage path. In this way, the proximity soundings were assumed to be representative of the environment immediately ahead of the derecho. Shear parameters were computed for the qualifying proximity soundings, using the vector difference between the winds at the surface and the top of the layer. Though this method differs from that used during the numerical simulations by Weisman (1992, 1993), where the length of the hodograph was the shear parameter, the vector difference is more robust when using an observational database, which does not necessarily have smooth hodographs. The 0-2-, 0-3-, and 0-6-km (all AGL) levels were chosen in an effort to investigate both the lower and deeper layer shear associated with these events. Hourly radar charts were then used to estimate the speed and direction of the convective systems, so that estimates of the lower- $(0-$ $2 \mathrm{~km})$, middle- (4-6 km), and upper- (6-10 km) level system-relative winds (SRWs) could be tabulated. Bulk Richardson number shear [referred to as BRN shear in this paper; Weisman and Klemp (1986); Droegemeier et al. (1993); Stensrud et al. (1997)] was also calculated for each sounding. BRN shear was defined as the magnitude of the difference between the 0-6-km densityweighted mean wind and the density-weighted mean wind of the lowest $0.5 \mathrm{~km}$.

Hourly surface observations were analyzed within 2 $\mathrm{h}$ before and after the corresponding sounding time. A few of the soundings located near the damage path were judged to have surface and/or boundary layer conditions unrepresentative of the inflow environment, owing to the presence of shallow storm outflow or a front. For these cases, the surface temperature and dewpoint of each sounding were modified to represent the surface conditions immediately ahead of the derecho. Soundings were only used if these modifications yielded surfacebased instability representative of the air mass maintaining the derecho. From these modified proximity soundings, CAPE and downdraft convective available potential energy (DCAPE) were computed. The virtual temperature correction was used in these calculations (Doswell and Rasmussen 1994). Surface potential temperature $(\theta)$ and surface equivalent potential temperature $\left(\theta_{e}\right)$ were also computed and plotted within $167 \mathrm{~km}$ and $2 \mathrm{~h}$ of each sounding. The differences between the minimum and maximum values of $\theta$ and $\theta_{e}$ across the derecho's outflow boundary, from the cold side to the inflow air mass, are investigated as reasonable proxies for cold pool strength in each event.

Since derechos can occur under a variety of synoptic regimes, the cases were classified into those associated with 1) weak synoptic-scale forcing and 2) strong synoptic-scale forcing. The "weak" and "strong" forcing categories correspond roughly to Johns's (1993) "warm season" and "dynamic" synoptic patterns associated with bow echo development. This was accomplished by obtaining the 1200 UTC 500-mb and surface charts prior to development, and assessing subjectively the strength of the forcing. Events that occurred ahead of an advancing high-amplitude midlevel trough and an accompanying strong surface cyclone were considered strong forcing (SF) (Fig. 1a). Those that occurred under relatively quiescent conditions were labeled as weak forcing (WF) events (Fig. 1b). Though low-level warm air advection can be considered a source of strong forcing in events categorized here as weak forcing, we have placed them under the WF label owing to their generally benign synoptic pattern, as shown in Fig. 1b. Events that did not fit clearly as either SF or WF were categorized as "hybrid" events (Fig. 1c).

Each sounding also was classified according to its location relative to the derecho life cycle. Those taken within the first $3 \mathrm{~h}$ of the derecho were categorized as "initiation" soundings; while those within $3 \mathrm{~h}$ of a derecho's demise were categorized as "end" soundings. Those in between were labeled "alongpath" soundings. The 3-h threshold was chosen to be roughly consistent with results of the numerical simulations of Weisman et al. (1988) and Weisman (1992, 1993), who found that simulated bow echoes entered their mature stage at around $3 \mathrm{~h}, 40 \mathrm{~min}$ from initiation.

\section{Results}

Using the preceding criteria, 67 derechos with at least one proximity sounding were identified. Derechos with proximity soundings were identified in nearly every month of the year over the 11-yr extent of the study, with $27 \mathrm{SF}$ and $30 \mathrm{WF}$ events (Fig. 2). Hybrid cases composed 10 events. In all, 113 soundings (47 SF, 51 WF, and 15 hybrid) fit our proximity criteria, an average of 1.7 soundings per derecho. The maximum number of proximity soundings from a single derecho is three. The addition of the 13 derechos in Johns et al. (1990) accompanied by proximity soundings tends to bias our results slightly in favor of warm season cases, since they only included events from May to August. However, 5 of these 13 derechos were classified as SF or hybrid, which should limit any bias in this dataset based on our decision to classify each event by forcing strength.

Figure 2 indicates that SF events occur in all seasons, with a relative maximum in the late spring. Weak forcing events, on the other hand, are confined to the warm season (May-Aug), consistent with the observations of Johns (1993). Hybrid events occur from June through October. The high-frequency axis found by JH87 across the northern states is evident in Fig. 3. Other axes extend southeastward across the southern plains and into the southern and middle Atlantic states, in agreement with the findings of Bentley and Mote (1998). 

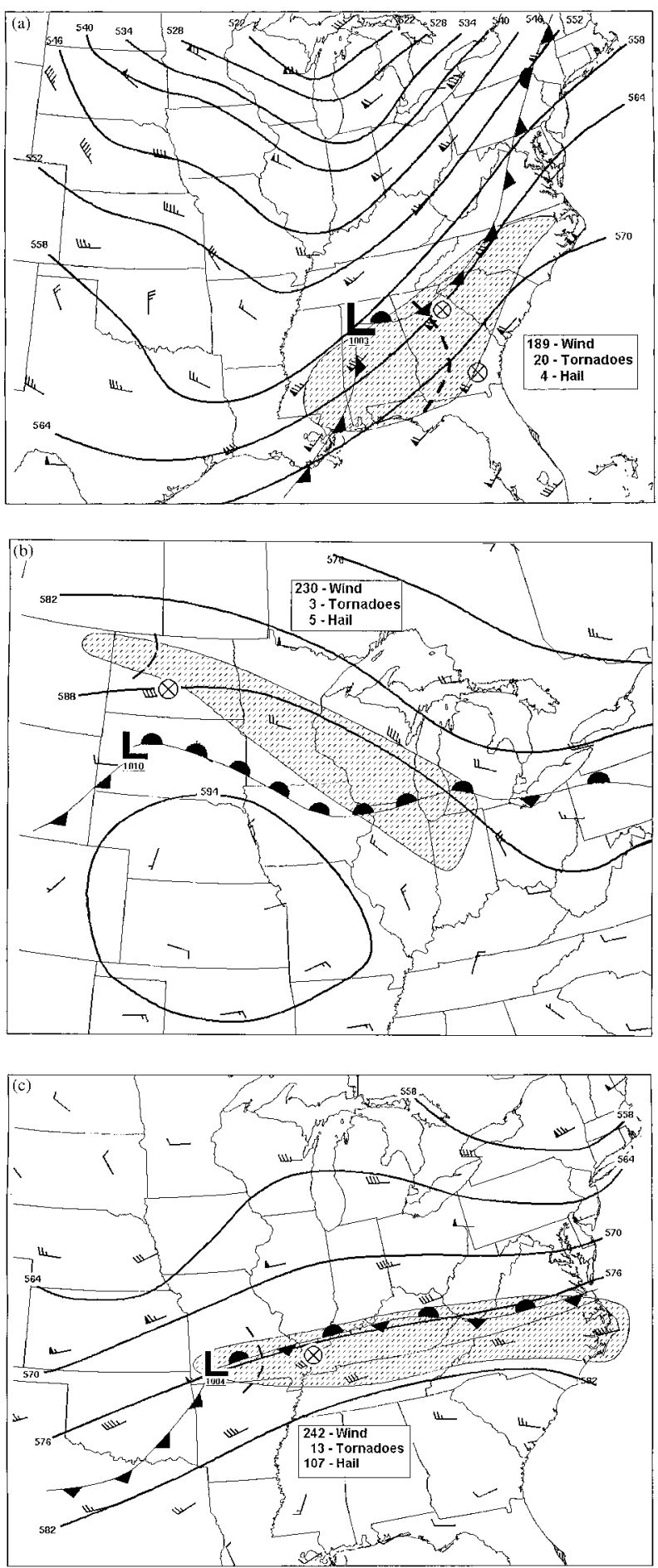

FIG. 1. Examples of the three derecho categories used in this paper. Solid lines depict 500-mb height contours, with the surface low center and frontal locations overlaid. Wind barbs are 500-mb winds. All data are at 1200 UTC, the morning prior to the derecho. Hatched area depicts the ensuing derecho's path, with the number of severe reports listed in the box. Dashed line represents the location of the derecho at 1200 UTC, with proximity sounding locations denoted by the $\times$ within a circle: (a) SF derecho on $10 \mathrm{Feb} 1990$, (b) WF derecho on 19 Jul 1983, and (c) hybrid derecho on 4 Jun 1993.

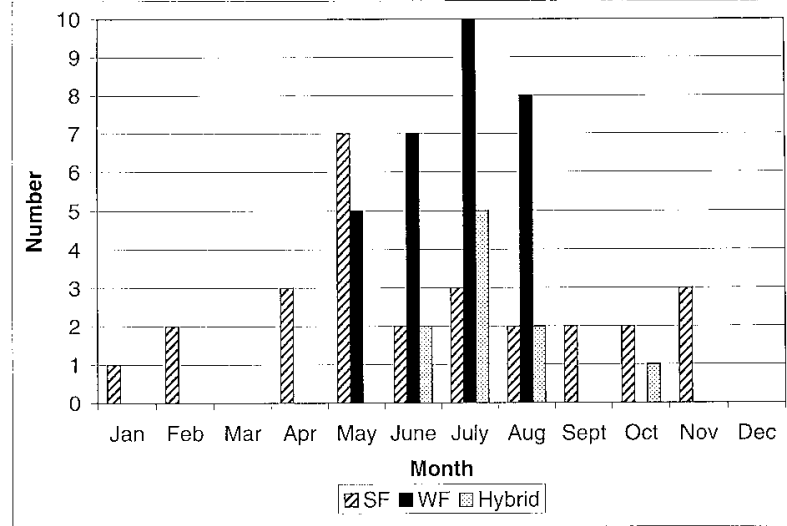

FIG. 2. Monthly distribution of derecho events with at least one proximity sounding for the years 1983-93. Events are separated by forcing type.

\section{a. Kinematics}

Vertical shear has been hypothesized to influence the ability of a gust front to initiate new convective cells in such a manner that produces a quasi-steady storm structure (Weisman and Klemp 1986). Since shear has been emphasized as an important parameter for bow echo longevity, we examined the shear profiles for each proximity sounding. Observed shear values from the proximity soundings have a wide range of values (Fig. $4)$. The $0-2-\mathrm{km}$ shear vector magnitudes range from near 3 to $30 \mathrm{~m} \mathrm{~s}^{-1}$, with the middle $50 \%$ of the distribution of shear vector magnitudes between 8 and $16 \mathrm{~m}$ $\mathrm{s}^{-1}$. The standard deviation is $5.8 \mathrm{~m} \mathrm{~s}^{-1}$. Figure 4 also shows that $0-3-\mathrm{km}$ shear vector magnitudes are very similar to the $0-2-\mathrm{km}$ values. The deep layer shear, defined as $0-6 \mathrm{~km}$ AGL here, has an even larger range

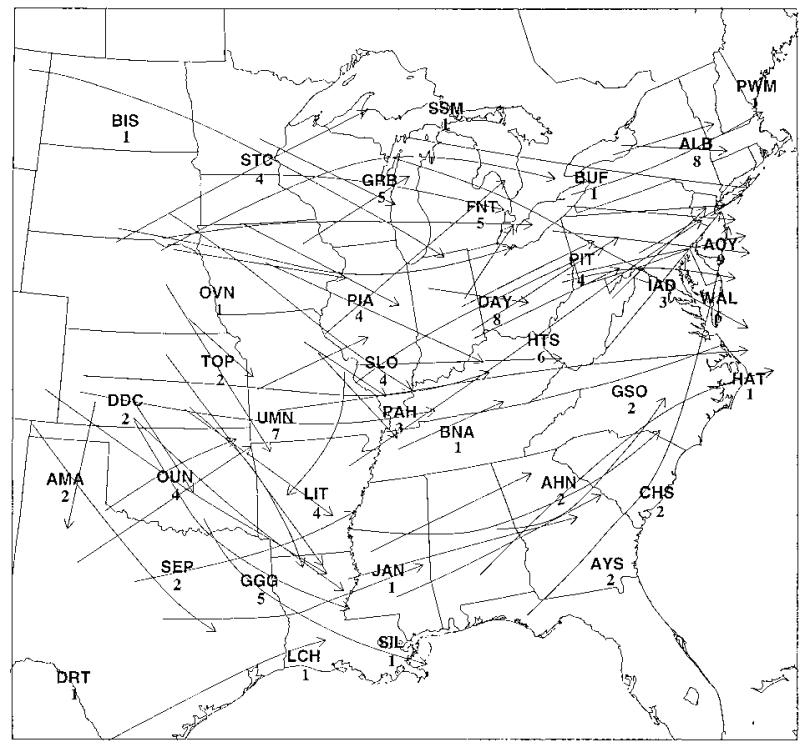

FIG. 3. Graphical plot of each derecho centroid, along with the number and location of proximity soundings used in this study. 


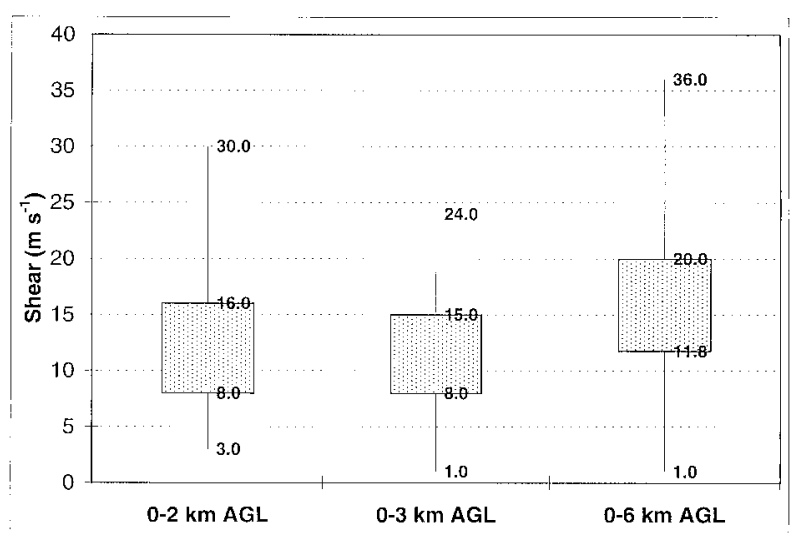

FIG. 4. Plot of the range of 0-2-, 0-3-, and 0-6-km (all AGL) shear associated with derechos. Box and whisker plot of shear vector magnitude with each sounding. Boxes denote the $50 \%$ of values between the 25 th and 75 th percentiles, with thin vertical line extending to the maximum and minimum values.

of values, with shear vector magnitudes ranging from 1 to $36 \mathrm{~m} \mathrm{~s}^{-1}$, and a standard deviation of $13.3 \mathrm{~m} \mathrm{~s}^{-1}$. These observed values of vector shear are generally weaker than the $2.5-5-\mathrm{km}$ shear values used in the idealized bow echo simulations by Weisman $(1992,1993)$ and those found by Johns et al. (1990).

When differentiating by large-scale forcing strength (Fig. 5), it is evident that SF events develop and persist in stronger shear environments than WF events, in general. Hybrid events usually occur within shear environments that lie between those of the WF and SF cases. Johns (1993) has noted that "dynamic" patterns (comparable to SF events in this study) can be accompanied by tornado outbreaks, which is consistent with the known preference for tornadoes to occur in strongly sheared environments. In fact, there are 314 tornadoes associated with SF events, compared to 126 tornadoes with WF cases. This yields an average near 11.5 tornadoes per SF event, but only 4 tornadoes for each WF event.

\section{b. System-relative winds}

In recent years, some studies have focused on ways to distinguish between tornadic and nontornadic supercells (Brooks et al. 1994a,b; Stensrud et al. 1997; Thompson 1998). Brooks et al. (1994b) have suggested that many supercells fail to produce sustained low-level mesocyclones and tornadoes because they become outflow dominated; that is, the cold pool undercuts the updraft, cutting off the moist inflow. Figure 6 shows that midlevel $(4-6 \mathrm{~km})$ SRWs are fairly weak with the derechos, especially with WF events. Average values of midlevel SRWs range from $7.5 \mathrm{~m} \mathrm{~s}^{-1}$ with WF events, to $11.5 \mathrm{~m} \mathrm{~s}^{-1}$ for SF cases. The average values of upperlevel $(6-10 \mathrm{~km}) \mathrm{SRWs}$ are 7.7 and $12.5 \mathrm{~m} \mathrm{~s}^{-1}$, respectively (not shown). A more detailed discussion on the relevance of the midlevel SRWs is deferred to section 6 .

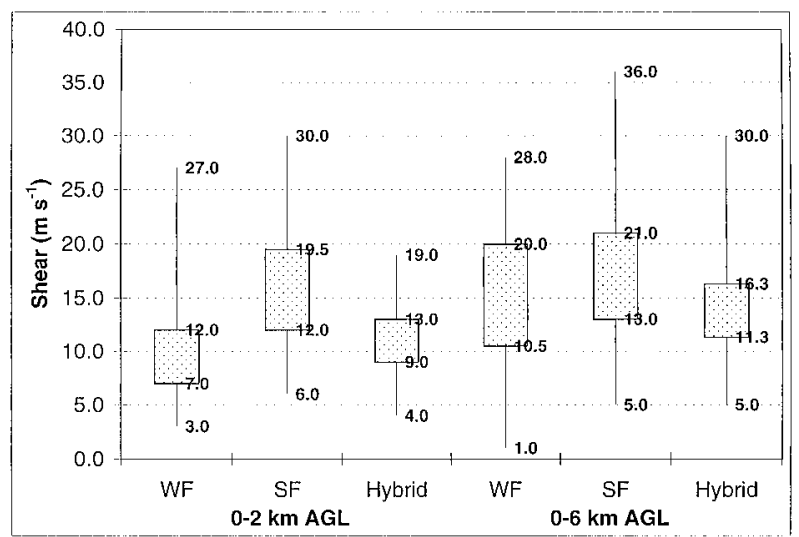

FIG. 5. As in Fig. 4 except for 0-2- and 0-6-km (all AGL) shear vector magnitudes with WF, SF, and hybrid events.

Despite the weaker mean flow (Fig. 7a) in WF events and the similar system speeds (Fig. 7b), Fig. 6 indicates that low-level system-relative inflow tends to be stronger in WF cases as compared to SF and hybrid events. This is consistent with "progressive" derecho environments found by JH87. The 0-2-km system-relative inflow exceeds $11 \mathrm{~m} \mathrm{~s}^{-1}$ for all but the lowest quartile of the cases in both WF and SF events, with median values of 16 and $14.5 \mathrm{~m} \mathrm{~s}^{-1}$, respectively. The rapid forward motion of bow echoes is responsible for much of the low-level system-relative inflow. However, the weak flow and shear in the WF events suggest a larger proportion of their forward motion and resultant increased low-level inflow might be attributed to new cell development along the leading edge of the rapidly moving cold pool, and not the mean airflow within the meso$\alpha$-scale (Orlanski 1975) environment supportive of convection. In other words, propagation plays an enhanced role in the motion of WF events, as has been postulated by JH87 and Corfidi (1998). In contrast, SF events likely owe a large proportion of their ground-relative motions to the stronger mean flow environments within which they exist.

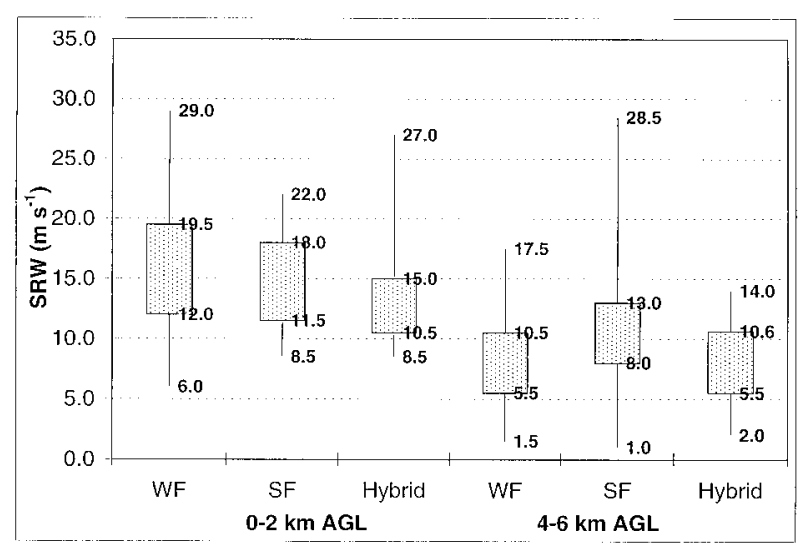

Fig. 6. As in Fig. 4 except for 0-2- and 4-6-km (AGL) systemrelative winds with WF, SF, and Hybrid events. 

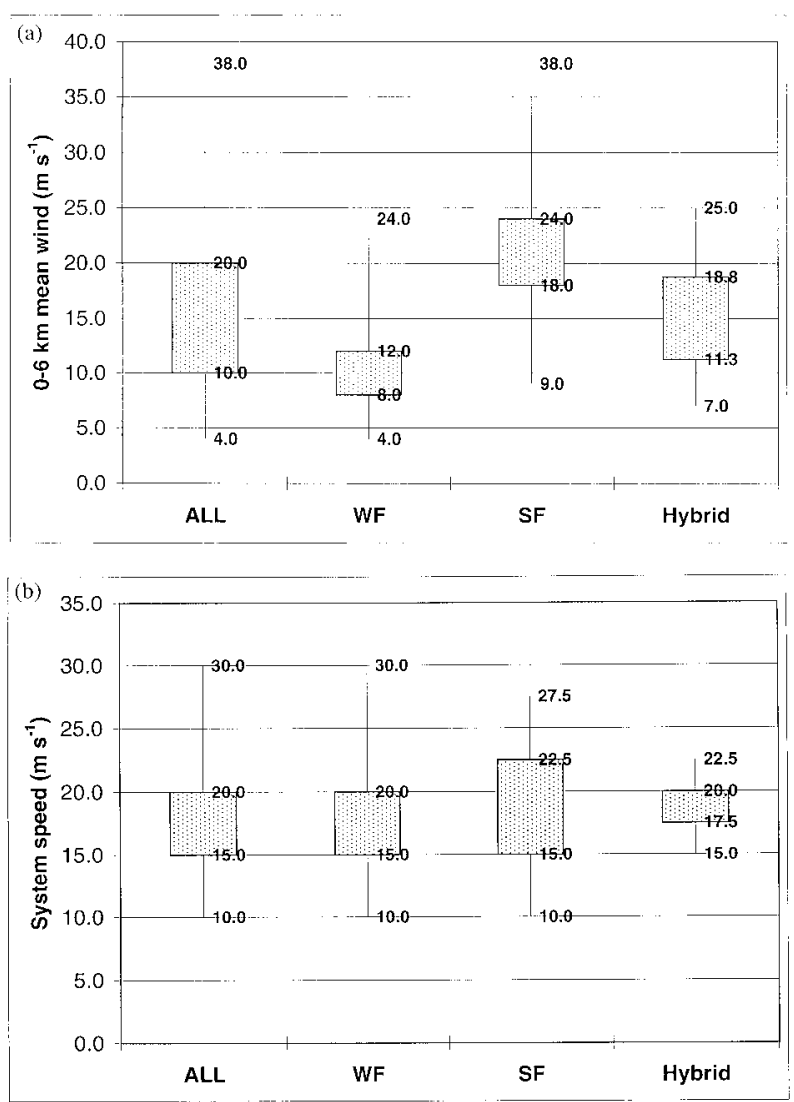

FIG. 7. As in Fig. 4 except for (a) 0-6-km (AGL) mean wind and (b) system speeds for all, WF, SF, and hybrid events.

Given the similarities between outflow-dominated supercells and enhanced cold pool development mentioned above, BRN shear is also considered for our derecho soundings. Stensrud et al. (1997) investigated BRN shear as a diagnostic tool to discriminate between tornadic and nontornadic thunderstorms without regard to storm motion, using a mesoscale model on nine severe weather events. They found that outflow-dominated convection, unsupportive of sustained low-level mesocyclones, is likely when BRN shear values are less than $40 \mathrm{~m}^{2} \mathrm{~s}^{-2}$, whereas low-level mesocyclones are favored with BRN shear values from 40 to $100 \mathrm{~m}^{2} \mathrm{~s}^{-2}$. However, Thompson (1998) found a wide range of BRN shear values associated with 131 observed tornadic and nontornadic supercells. Thompson indicated that the majority of nontornadic (and therefore more likely to be outflow dominated) supercells were associated with BRN shears from 20 to $50 \mathrm{~m}^{2} \mathrm{~s}^{-2}$, with $39 \%$ exceeding the $40 \mathrm{~m}^{2} \mathrm{~s}^{-2}$ threshold suggested by Stensrud et al. (1997). Figure 8 reveals that three-fourths of our proximity soundings associated with derechos had BRN shear values less than $55 \mathrm{~m}^{2} \mathrm{~s}^{-2}$, with $50 \%$ of the soundings between 16 and $55 \mathrm{~m}^{2} \mathrm{~s}^{-2}$. This is very similar to Thompson's findings regarding BRN shear values associated with nontornadic supercells, although it over-

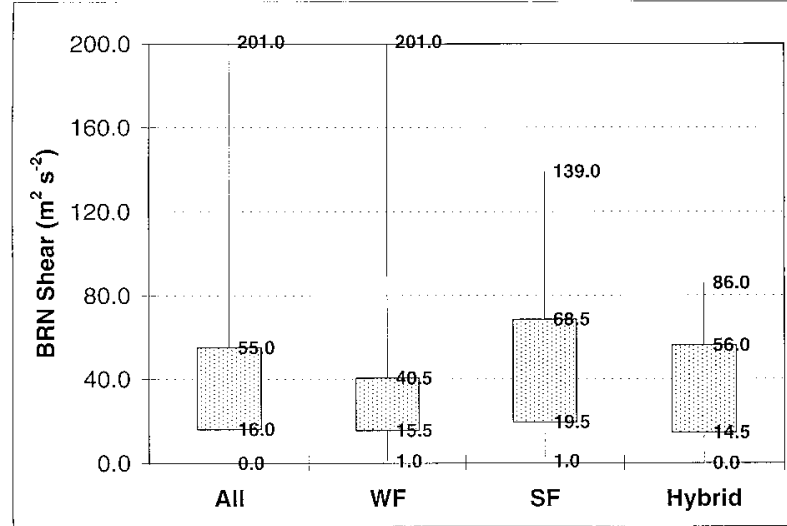

FIG. 8. As in Fig. 4 except for bulk Richardson number shear for all, WF, SF, and hybrid events.

laps the $40 \mathrm{~m}^{2} \mathrm{~s}^{-2}$ threshold found by Stensrud et al. to distinguish between tornadic and nontornadic supercells. When considering only WF events, the 75th percentile value drops to $40.5 \mathrm{~m}^{2} \mathrm{~s}^{-2}$, which is close to the threshold found by Stensrud et al.

Therefore, when synoptic-scale forcing is weak, BRN shear is similar to the midlevel SRW in suggesting a predominance of outflow-dominated convection in derecho environments. However, for the SF events, the value of BRN shear appears to become less valuable as a tool to discriminate bow echo development from environments conducive to supercell tornadoes. This is due to the large number of SF cases exceeding the upper thresholds of BRN shear for nontornadic supercells suggested by both Stensrud et al. and Thompson.

\section{c. Thermodynamics}

CAPE has been computed using both a mean-mixed layer parcel over the lowest $100 \mathrm{mb}$ (MLCAPE), and the most unstable parcel in the lowest $300 \mathrm{mb}$ (MUCAPE). MUCAPE values generally are larger than the MLCAPE calculation, reaching extreme values in some cases. Both the MUCAPE and MLCAPE values (Fig. 9) are greater on average for the WF events than the SF events; WF events are primarily warm season occurrences (Fig. 2) when instability tends to be larger, as suggested in JH87 and Johns et al. (1990). Lapse rates associated with the derechos in this study exhibit larger average midtropospheric $(700-500 \mathrm{mb})$ values $\left(7.3^{\circ} \mathrm{C}\right.$ $\left.\mathrm{km}^{-1}\right)$ in the WF cases than in the SF cases $\left(6.7^{\circ} \mathrm{C}\right.$ $\left.\mathrm{km}^{-1}\right)$.

Most of the WF events display CAPE values within the range that Weisman (1993) established with longlived bow echo simulations, and JH87 and Johns et al. (1990) found to be associated with derechos. Only 7 of the 51 soundings associated with WF events have MUCAPE values below Weisman's (1993) minumum threshold of $2000 \mathrm{~J} \mathrm{~kg}^{-1}$. Whereas surface-based conditional instability is present in most of the cases, as 

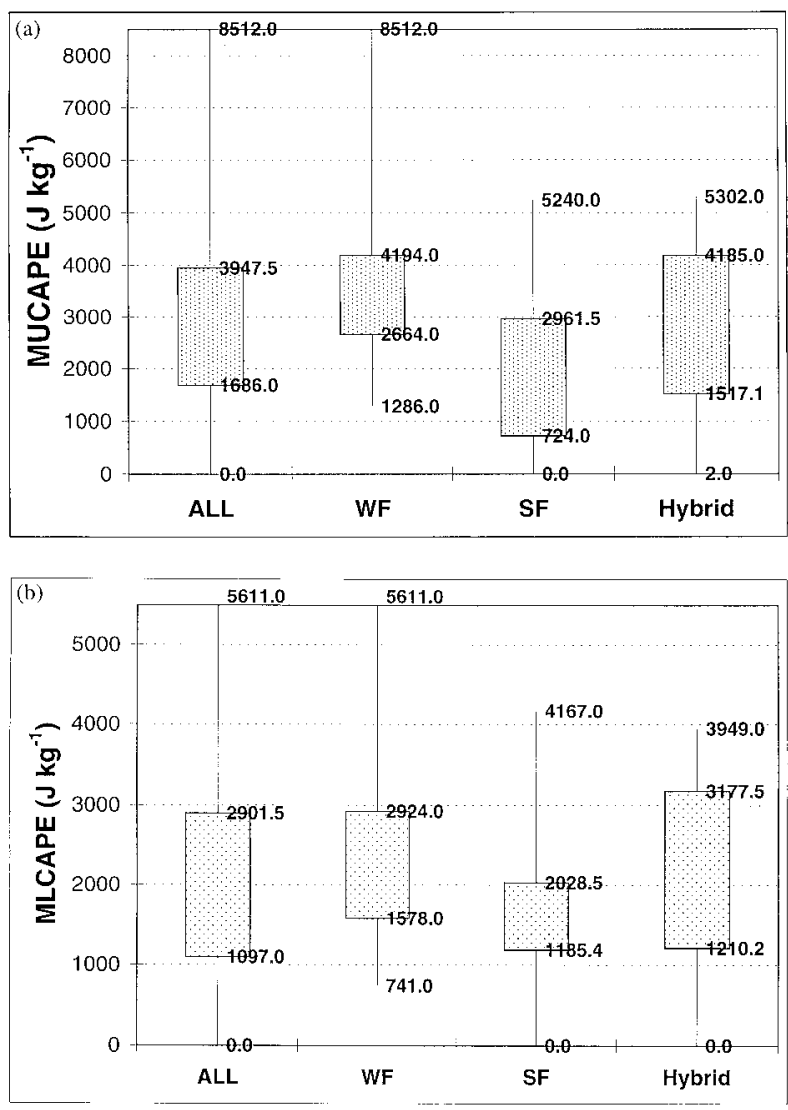

FIG. 9. As in Fig. 4 except for (a) CAPE generated by lifting the most-unstable parcel (MUCAPE) and (b) CAPE generated by lifting a mean-mixed parcel through the lowest $100 \mathrm{~m}$ (MLCAPE). Both plots use the virtual temperature correction.

revealed by the generally high values of MLCAPE, a few derechos develop and persist within regions of conditionally stable surface air. In these cases, the conditional instability is elevated above the surface layer (e.g., JH87; Schmidt and Cotton 1989). Figure 9 reveals that most WF derechos occur with relatively high MLCAPE or MUCAPE values, but SF events often are associated with MUCAPE values less than $2000 \mathrm{~J} \mathrm{~kg}^{-1}$; some SF cases have very small values of MUCAPE (approaching $0 \mathrm{~J} \mathrm{~kg}^{-1}$ ).

The surface potential temperature $(\theta)$ and surface equivalent potential $\left(\theta_{e}\right)$ differences across the derecho's outflow boundary have been used to estimate the strength of the cold pool produced by convective downdrafts. The maximum differences of $\theta(\Delta \theta)$ and $\theta_{e}\left(\Delta \theta_{e}\right)$ across the gust front are calculated within $167 \mathrm{~km}(100$ $\mathrm{mi}$ ) and $2 \mathrm{~h}$ of each sounding. Twelve of the $47 \mathrm{SF}$ cases $(25 \%)$ had no noticeable surface $\theta\left(\theta_{e}\right)$ minimum within the cold pool, as these events were aligned along a strong cold front with progressively lower surface $\theta\left(\theta_{e}\right)$ values behind the front. For these cases, the surface $\theta$ $\left(\theta_{e}\right)$ value immediately behind the cold front was used. Figure 10 shows that WF events typically produce greater surface $\Delta \theta_{e}$ (and to a lesser degree, $\Delta \theta$ ) than SF
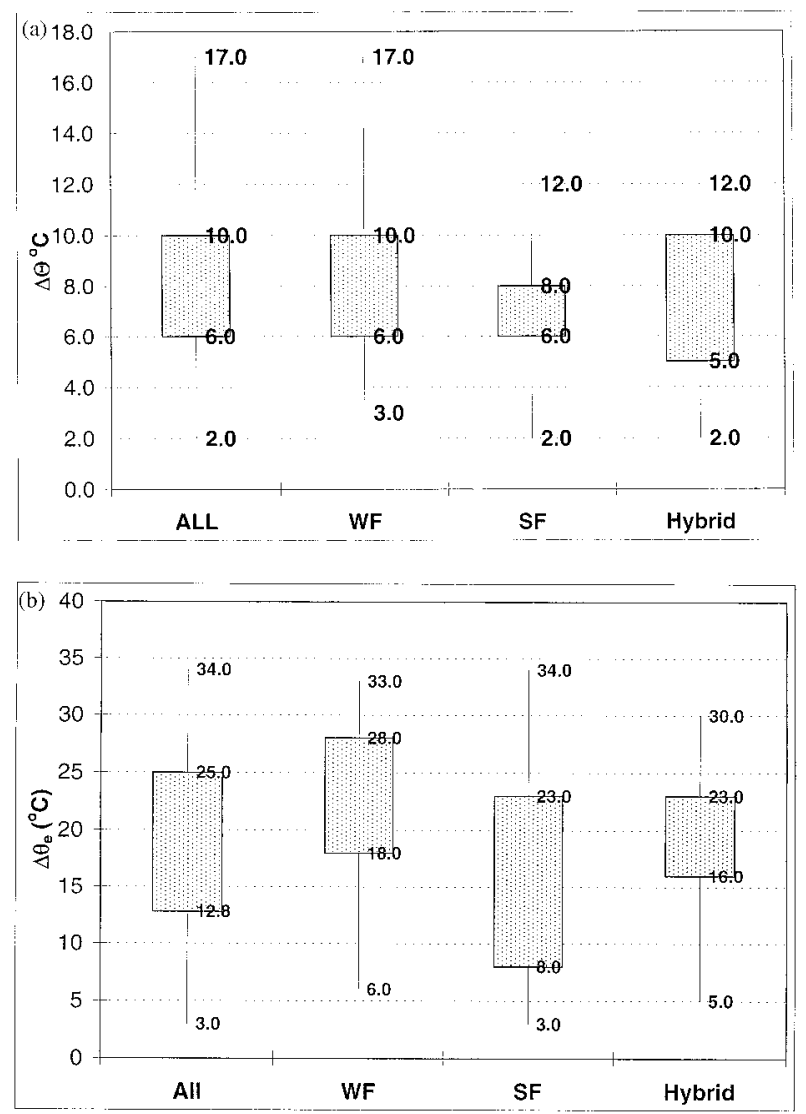

FIG. 10. As in Fig. 4 except for difference in (a) surface potential temperature $(\Delta \theta)$ and (b) surface equivalent potential temperature $\left(\Delta \theta_{e}\right)$. Differences of each parameter are taken between the maximum value of the ambient environment immediately ahead of the outflow boundary and the minimum value within the cold pool for all, WF, SF, and hybrid events.

events. This suggests stronger cold pools accompany the WF cases, although considerable overlap between $\mathrm{SF}$ and WF events can be seen. The median values of surface $\Delta \theta\left(\Delta \theta_{e}\right)$ were $8^{\circ} \mathrm{C}\left(22^{\circ} \mathrm{C}\right)$ in WF events and $7^{\circ} \mathrm{C}\left(14^{\circ} \mathrm{C}\right)$ for the SF cases.

A second method to estimate cold pool strength uses downdraft convective available potential energy [DCAPE; Emanuel 1994], as formulated by Gilmore and Wicker (1998). It generally is understood that entrainment of dry air into downdrafts strengthens them through increased evaporative cooling (Fawbush and Miller 1954; Foster 1958; Browning and Ludlam 1962; Hookings 1965). Therefore, DCAPE can be considered as an estimate of the potential cold pool strength for a sounding; in situations where a sounding precedes the event, DCA$\mathrm{PE}$ provides an estimate of cold pool strength before development. Gilmore and Wicker (1998) describe a number of caveats concerning the use of DCAPE as a proxy for cold pool strength, primarily that the entrainment of environmental air violates parcel theory by diluting the downdraft and changing the $\theta_{e}$ of parcels. We concur with those concerns, but we are only using this 


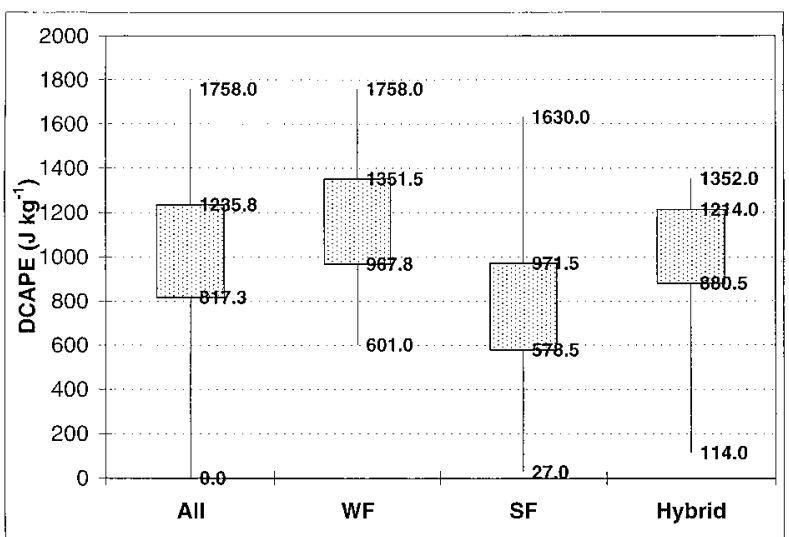

FIg. 11. As in Fig. 4 except for DCAPE for all, WF, SF, and hybrid events.

index in a qualitative sense, to estimate when one cold pool may be stronger than another. When comparing DCAPE values by forcing type (Fig. 11), the pattern is similar to that found by using the surface $\Delta \theta$ and $\Delta \theta_{e}$ (Fig. 10). DCAPE is noticeably higher with the WF cases, which resembles the CAPE relationship shown in Fig. 9. Using DCAPE as a proxy for cold pool strength seems justified by Fig. 12, which exhibits a roughly linear relationship between DCAPE and both the surface $\Delta \theta$ and $\Delta \theta_{e}$ in these cases; the linear correlation coefficient is near 0.5 for both these relationships.

\section{d. Kinematic and thermodynamic relationship}

Previous studies regarding supercell environments (Rasmussen and Wilhelmson 1983; Turcotte and Vigneux 1987; Johns et al. 1993, among others) have found that supercells occur in both very weak and very strong conditional instability environments. In very general terms, they found an inverse relationship between shear and instability; that is, strong shear tends to be associated with the weak instability cases, and vice versa. Our study shows a similar relationship between shear and instability within derecho environments, which is consistent with Weisman's (1993) findings for his simulated bow echoes. The proximity soundings are divided into three categories of MUCAPE depending on percentile rank. The 25th percentile of MUCAPE is used to designate the upper value of weak instability cases, whereas the 75th percentile of MUCAPE forms the bottom value of strong instability events. Those events between the 25th and 75th percentile values are labeled as "moderate" instability. The range of shear associated with each of these instability categories (Fig. 13) shows when the instability is weak, the shear is stronger, on average. This relationship is most apparent for the lowlevel shear values, although there is a suggestion of a similar relationship for the deep layer shear.

Figure 14 suggests the existence of an inverse rela-
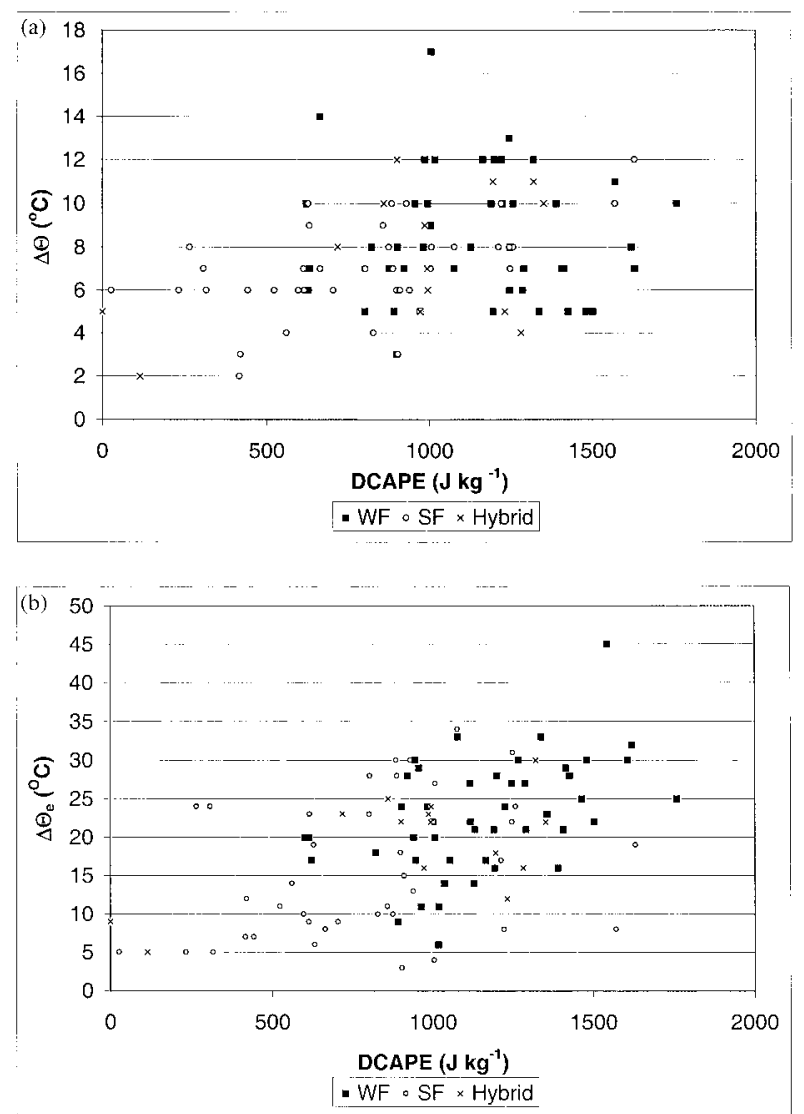

FIG. 12. Scatterplot of DCAPE values vs associated maximum of (a) $\Delta \theta$ and (b) $\Delta \theta_{e}$ across each cold pool. Each plot is annotated with its corresponding large-scale forcing type.

tionship between DCAPE and mean wind when considering all derechos. Careful examination of this figure shows that this is the result of the separation into SF, WF, and hybrid categories. The SF cases are found in the upper-left part of the figure, the WF cases are found

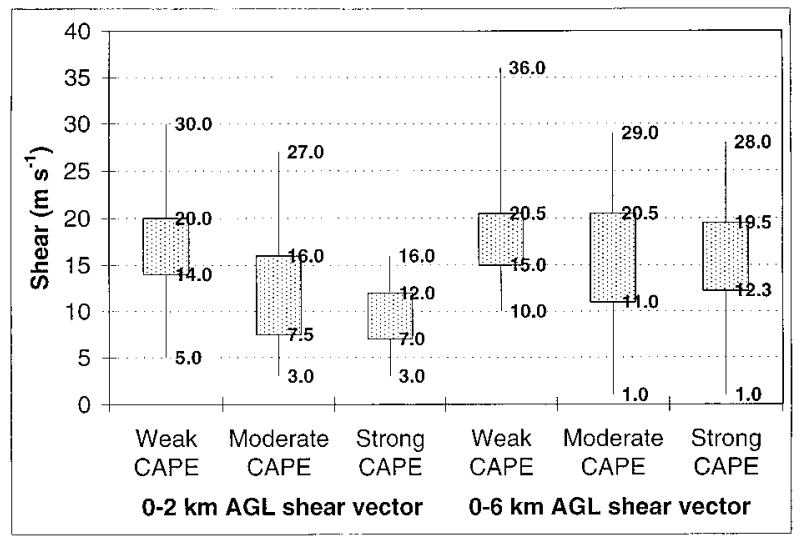

FIG. 13. As in Fig. 4 except for $0-2-$ and $0-6-\mathrm{km}$ shear vector magnitudes distributed in varying MUCAPE environments. Weak, moderate, and strong categories represent MUCAPE classified by percentile rank in Fig. 9a (see text). 


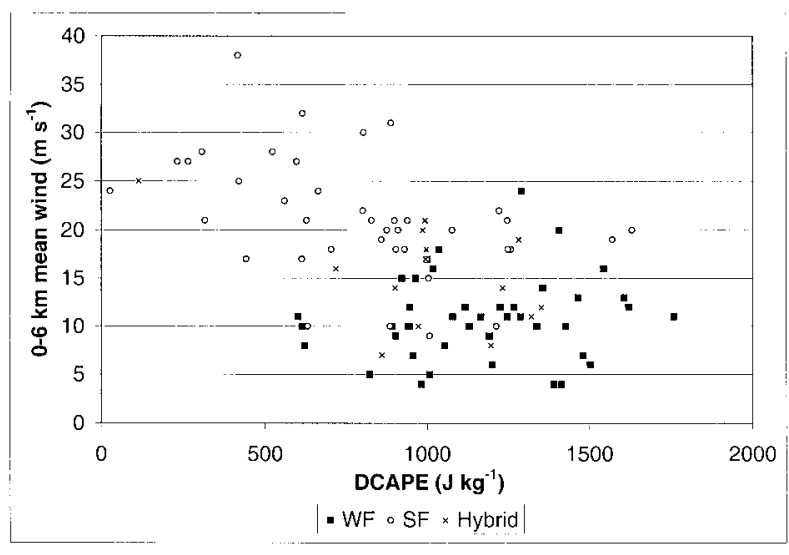

FIG. 14. Scatterplot of DCAPE vs 0-6-km mean wind. Each plot is classified by forcing type.

in the lower-right part, and the hybrid cases are in between, with some hint that they are more like the WF cases than the SF cases. If this relationship is viewed in terms of the $0-6-\mathrm{km}$ shear instead of the $0-6-\mathrm{km}$ mean wind (Fig. 15), a similar separation among the categories is found. Though a modest linear correlation exists between DCAPE and 0-6-km shear, the relationship is not as clear cut as that between DCAPE and 06-km mean wind.

It is of some interest to consider how shear varies with the mean wind for our cases; it can be argued that shear and mean wind ought to be related. However, Fig. 16 reveals that the WF and SF events are distinguished primarily by their $0-6-\mathrm{km}$ mean wind values; within each category, the $0-6-\mathrm{km}$ shear can vary widely. The hybrid cases again seem to fall more or less in between the SF and WF distributions and, like the WF and SF events, do not validate a strong shear-mean wind relationship.

\section{Comparison of observations with numerical simulations}

Through idealized numerical simulation experiments using a nonhydrostatic cloud model, Weisman (1992, 1993) has suggested that long-lived bow echoes favor a "restricted range of environmental conditions with CAPE of at least $2000 \mathrm{~m}^{2} \mathrm{~s}^{-2}$ and vertical wind shears of at least $20 \mathrm{~m} \mathrm{~s}^{-1}$ in the lowest $2.5-5 \mathrm{~km} \mathrm{AGL.} \mathrm{.} \mathrm{."}$ Weisman further asserts that long-lived bow echoes especially favor environments where the majority of the shear is confined to the lowest $2.5 \mathrm{~km}$. He proposes that these CAPE and shear environments favor the development of an elevated rear-inflow jet, once the cold pool circulation becomes stronger than that of the ambient shear and allows the system to develop an upshear-tilted structure. The elevated rear-inflow jet then "rebalances" the circulations of the cold pool and low-level shear, which supports deep, vertical convection along the leading edge of the cold pool. This hypothesis expands upon

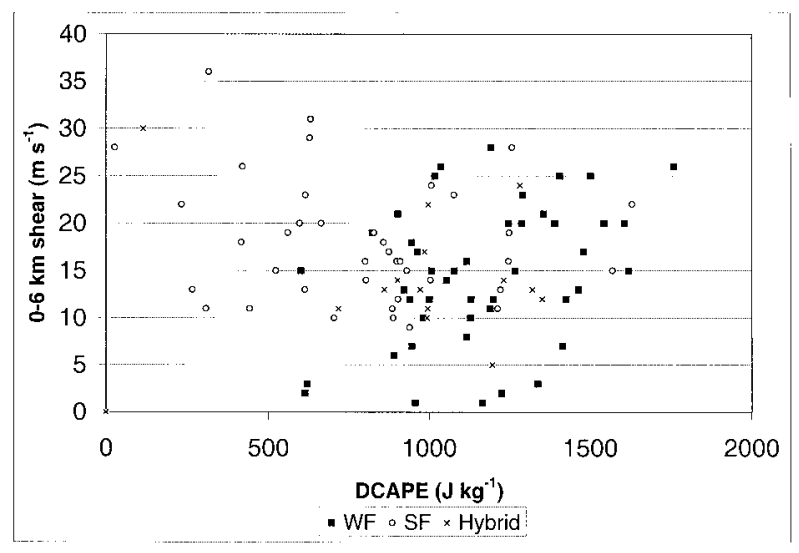

FIG. 15. As in Fig. 14 except for DCAPE vs 0-6-km shear.

the conceptual model proposed initially in RKW, which uses a shear versus cold pool balance to define an optimum environment for long-lived severe squall lines. Since a shear-outflow balance has been emphasized in the work using numerical simulations (RKW; Weisman et al. 1988; Weisman 1992, 1993), we wish to investigate whether or not the derechos in our dataset occurred within optimum conditions for long-lived squall lines as defined by RKW. It should be noted that the presence or absence of rear-inflow jets to rebalance the cold pool and shear, as proposed by Weisman (1993) for long-lived bow echoes, cannot be determined from our dataset.

RKW uses the buoyancy distribution as an estimate of the cold pool strength, which corresponds to the magnitude of the cold pool circulation at its leading edge. We feel the surface $\Delta \theta$ should be closely related to the buoyancy distribution used by RKW, and is a reasonable operational proxy for their estimate of cold pool strength and the corresponding magnitude of the horizontal circulation generated. RKW theory also employs the shear over a layer corresponding to the depth of the cold pool, which makes a direct comparison using operationally

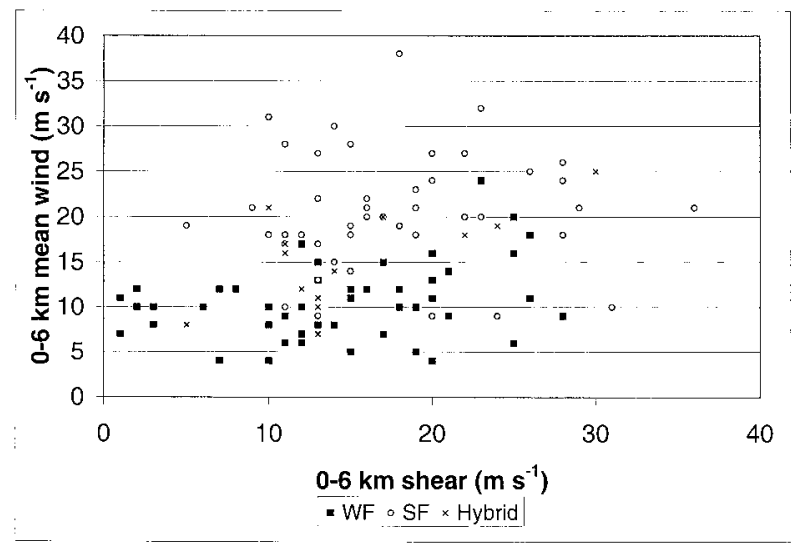

Fig. 16. As in Fig. 14 except for $0-6-\mathrm{km}$ shear vs $0-6-\mathrm{km}$ mean wind. 

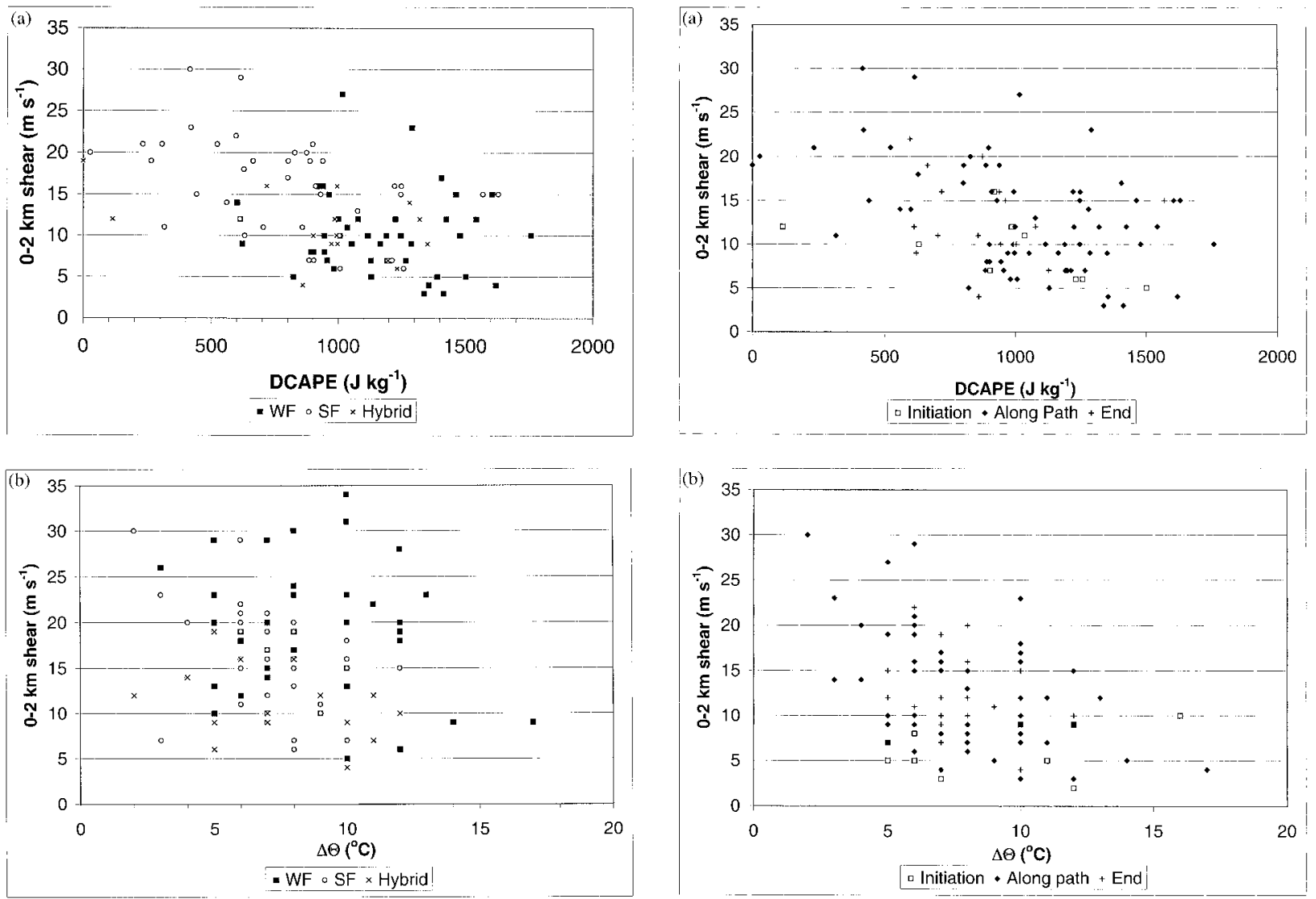

Fig. 17. As in Fig. 14 except for (a) DCAPE vs 0-2-km shear vector magnitude and (b) surface $\Delta \theta$ across the cold pool vs $0-2$ km shear.

available data difficult. As a simple estimate, we have used the $0-2-$ and $0-3-\mathrm{km}$ low-level vector shears as proxy variables for the shear over the depth of the cold pool.

Figure 17 reveals that our data show a significantly different picture of this relationship than that suggested by RKW; virtually no positive correlation is apparent between our proxies for the shear and cold pool strength. Linear correlation coefficients are -0.45 for DCAPE and -0.32 for surface $\Delta \theta$, with linear correlation coefficients of -0.11 and -0.15 , respectively, for just the WF events that are the most likely to be sustained by strong cold pools. Similar results are obtained when using the 0-3-km shear (not shown).

We stratified our soundings into categories based on the time within the life cycle of a derecho, in order to refine our analysis accordingly. The results (Fig. 18) show that the proximity sounding location relative to the life cycle of the derecho is not responsible for the absence of a positive correlation between low-level shear and cold pool strength, using our operationally available proxies. This supports the findings of Weisman (1993), who suggests the cold pool and ambient shear circulations are not optimal within his simulated bow

FIG. 18. As in Fig. 14 except classified by life cycle stage of bow echo associated with each sounding.

echoes. However, the hypothesis that an elevated rearinflow jet is necessary to rebalance the circulations of the cold pool and ambient shear cannot be proved (or disproved) using our operational observations.

\section{Comparison with nonderecho MCS cases}

To gain a better understanding of environmental factors contributing to bow echoes, 13 mesoscale convective systems (MCSs) that did not meet the criteria to be defined as long-lived derechos have been investigated. In fact, these cases produced little or no severe weather [i.e., hail $\geq 0.75$ in. $(2 \mathrm{~cm})$, wind $\geq 50 \mathrm{kt}\left(25 \mathrm{~m} \mathrm{~s}^{-1}\right)$, or tornadoes]. All the nonderecho events affected the Great Plains during the warm season and occurred under weak synoptic-scale forcing. Therefore, the environments associated with these nonderecho MCSs are comparable only to the WF derecho events. When the same proximity criteria are applied to these events, 31 soundings are obtained near nonderecho MCS's.

The MUCAPE and DCAPE from the 31 proximity soundings for the nonderecho MCSs suggest that most of these events develop within similar thermodynamic environments to those associated with WF derechos (Fig. 19). However, Fig. 20 indicates that the deep layer 


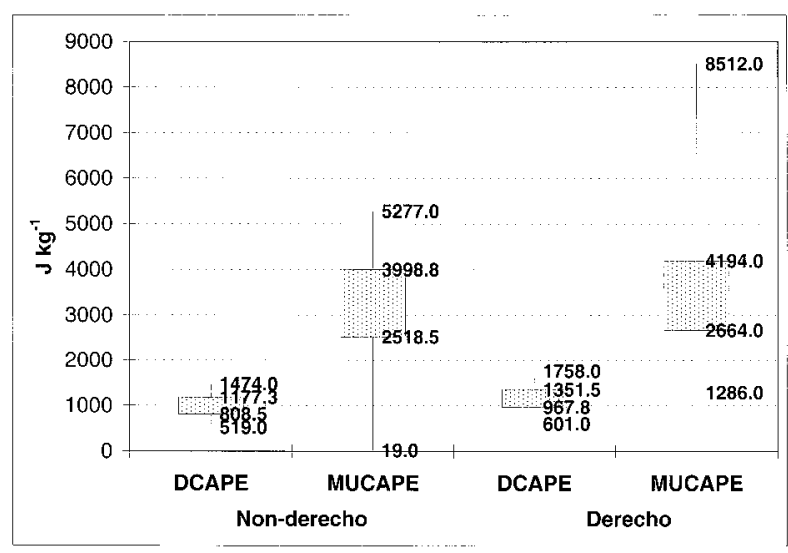

FIG. 19. As in Fig. 4 except for DCAPE and MUCAPE associated with the nonderecho and the WF derecho-producing MCSs.

mean winds are weaker and the system speeds are slower with the nonderecho MCSs, when compared to the derecho events. The same can be said for the 0-2- and $0-$ 6-km shear values (Fig. 21).

Figure 22 indicates that the $0-2-\mathrm{km}$ system-relative inflow is stronger with the derecho events than the nonderecho MCSs (likely due to the faster system speeds of the derechos), although the 4-6-km SRWs are not markedly dissimilar between the two datasets. The comparable thermodynamic and similar midlevel SRW environments indicate both WF derechos and nonderecho MCSs occur within surroundings considered to be favorable for outflow-dominated convection and strong cold pools. These results suggest the environmental conditions favoring strong cold pools do not appear to be sufficient by themselves to distinguish between derechos and nonderecho MCSs, at least when large-scale forcing is weak. Other factors likely aid in maintaining severe wind gusts at the surface in addition to the cold pool potential. The most obvious factor within this dataset appears to be the strength of the mean flow, which ap-

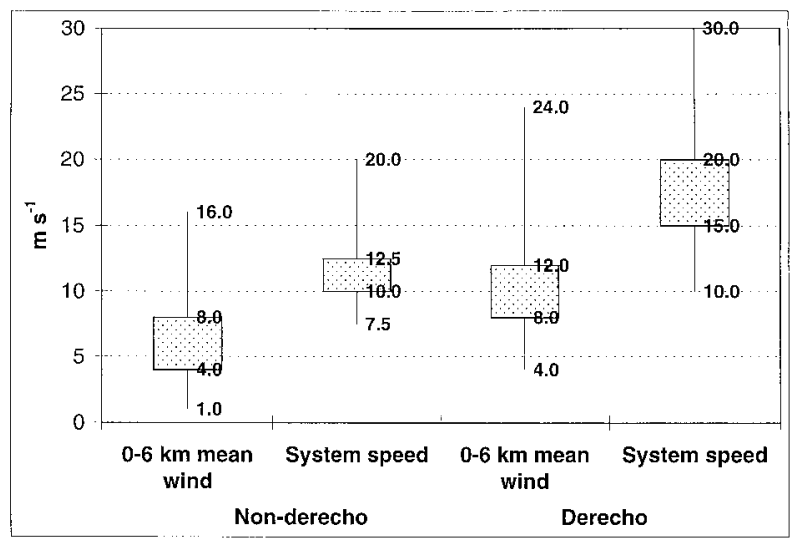

FIG. 20. As in Fig. 4 except for $0-6-\mathrm{km}$ mean wind and speed of forward movement of both nonderecho and derecho producing WF events.

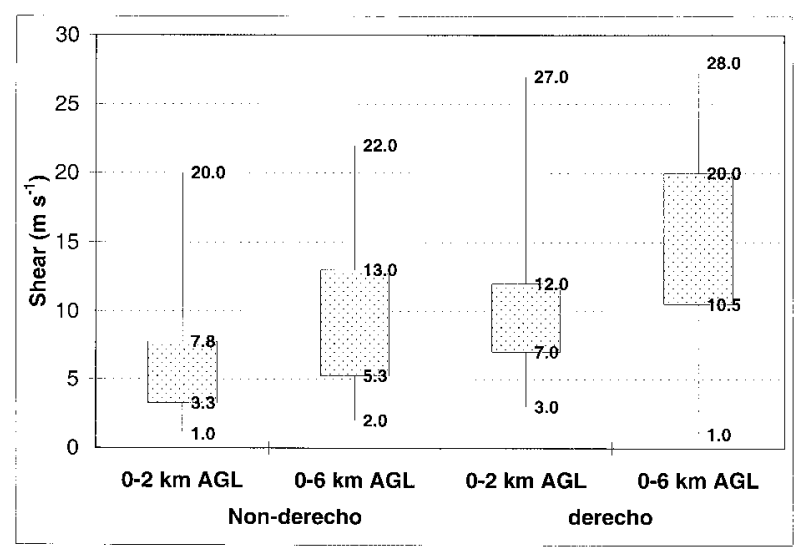

FIG. 21. As in Fig. 4 except for 0-2- and 0-6-km shear vectors for both nonderecho and derecho producing WF events.

pears to affect the $0-2-\mathrm{km}$ SRW, as well as the forward movement speed of the cold pool and associated storms.

\section{Discussion and conclusions}

Long-lived convective windstorms occur throughout the year within a wide range of environments, covering large portions of the CAPE-shear parameter space. Our results indicate that synoptic-scale forcing plays an important role in supporting some types of convective windstorms. When strong synoptic-scale forcing is present, mean deep layer flow and deep layer shear are usually stronger, while instability is typically much weaker than for cases occurring within "benign" synoptic-scale environments. In fact, MUCAPE values $<1000 \mathrm{~J} \mathrm{~kg}^{-1}$ are observed with more than $25 \%$ of SF cases. This suggests that when a high-amplitude, midlevel trough and an accompanying strong surface cyclone are present, long-lived convective windstorms can occur within weak CAPE and DCAPE environments. In these situations, other factors besides CAPE and DCA$\mathrm{PE}$ are apparently important in producing damaging sur-

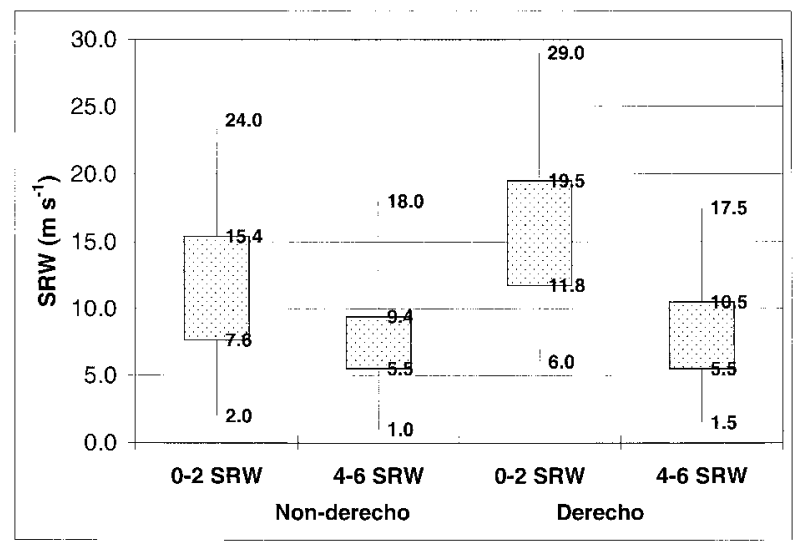

FIG. 22. As in Fig. 4 except for 0-2- and 4-6-km SRWs associated with WF nonderecho and derecho events. 

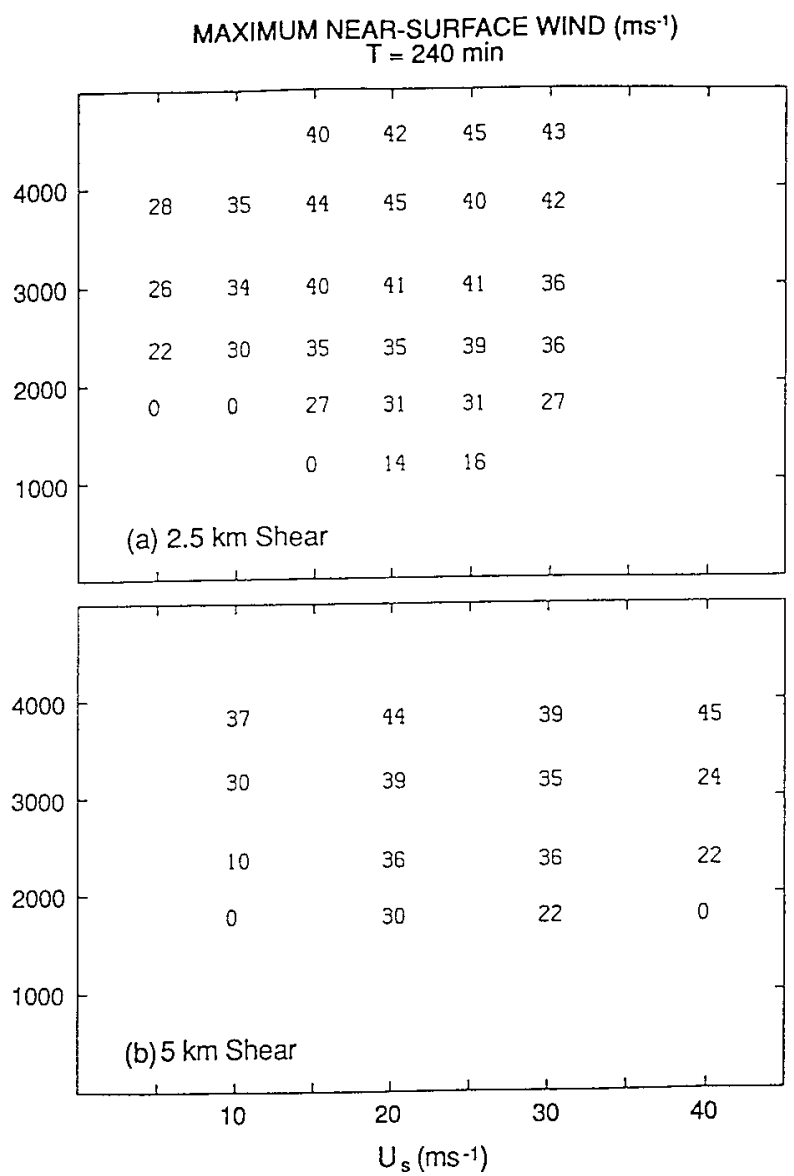

Fig. 23. Maximum near-surface $(350 \mathrm{~m})$ wind $\left(\mathrm{m} \mathrm{s}^{-1}\right)$ for the (a) 2.5- and (b) 5-km shear from Weisman's numerical simulation (after Fig. 25 in Weisman 1993, plotted against corresponding CAPE used. Weisman considered severe surface winds to occur with $350-\mathrm{m}$ winds of $35 \mathrm{~m} \mathrm{~s}^{-1} . U_{s}$ represents the maximum magnitude of the wind for each wind profile.

face winds. In contrast, when synoptic-scale forcing is more innocuous, much higher values of CAPE and DCAPE appear necessary to maintain a sustained convective wind threat. Three-fourths of the WF events occurred within MUCAPE values more than $2600 \mathrm{~J}$ $\mathrm{kg}^{-1}$.

Shear values from the 0-2-, 0-3-, and 0-6-km layers exhibit a wide range of values for the 67 derechos examined, though the consistent differences between the low and midlevel SRWs indicate ground-relative shear is found somewhere in the lowest $6 \mathrm{~km}$ in nearly all our derecho cases. Three-fourths of all the derechos occurred with $0-2-\mathrm{km}$ shear vector magnitudes less than $16 \mathrm{~m} \mathrm{~s}^{-1}$, and values ranged from near 3 to $30 \mathrm{~m} \mathrm{~s}^{-1}$. Most of these events also developed and persisted within $0-6-\mathrm{km}$ shear vector magnitudes less than $20 \mathrm{~m} \mathrm{~s}^{-1}$. These shear values are even observed with WF events, where strong cold pools and high values of CAPE are common. Figure 23 reveals the range of CAPE and shear Weisman (1993) found to be associated with near-sur-
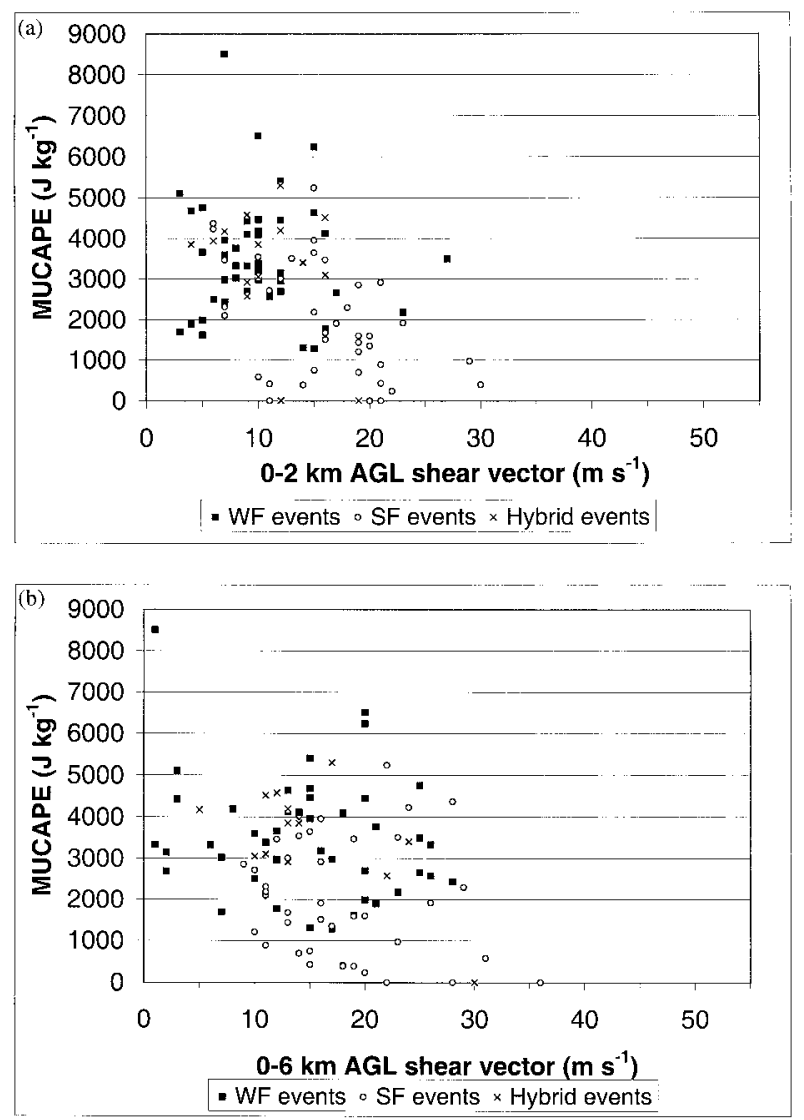

FIG. 24. Plot of the observed range of (a) $0-2-\mathrm{km}$ shear vector and (b) 0-6-km shear vector from alongpath proximity soundings associated with mature derechos, plotted against corresponding MUCAPE. Each plot is categorized by the strength of the associated synoptic-scale forcing.

face wind from a mature bow echo within his numerical cloud model. Our alongpath proximity soundings near mature derechos (Fig. 24) indicate a range of CAPEshear environments that is greater than the range considered during Weisman's numerical bow echo simulations, particularly with regard to the shear in the WF events. In addition, when estimates of cold pool strength are compared to the corresponding low-level shear vectors, the results suggest a shear versus cold pool balance is not evident within the range of cases we have seen in an operational environment. This would suggest the majority of our cases exist in environments that are not optimum for long-lived squall lines using the RKW model, as is further implied by Weisman's (1993) simulations, which indicate that the circulation of the cold pool becomes dominant as the convective system transitions to a bow echo. Our observations appear to be more consistent with the findings of Garner and Thorpe (1992), who found in their simulations that neither the low-level vorticity nor the depth of the shear layer is by itself a good predictor of squall line development.

Examination of the system-relative winds reveal that they have a more consistent association with long-lived 
bow echoes than the low-level shear. Recall that Brooks et al. (1994b) and Thompson (1998) have suggested that storms with weak midlevel storm-relative winds should produce an outflow-dominated storm. In unstable environments that are not excessively capped, new cells then can develop along the outflow boundary. Large convective systems such as bow echoes obviously are quite different from supercells; however, the results of our study suggest storm-scale SRW arguments may yet be useful in explaining long-lived bow echo behavior.

In most derecho environments, we have shown that the 4-6-km SRWs are consistently weak when compared to the low-level SRWs (Fig. 6). Although strong low-level inflow is observed to be common, with average $0-2-\mathrm{km}$ SRWs in excess of $15 \mathrm{~m} \mathrm{~s}^{-1}$, midlevel (4-6 km) SRWs are, on average, much weaker $(9 \mathrm{~m}$ $\left.\mathrm{s}^{-1}\right)$. This is most pronounced in the WF cases, though the majority of SF and hybrid events also reveal the same weakness in the midlevel SRW. Thompson (1998) found that only $19 \%$ of his tornadic supercell cases occurred within 500-hPa SRWs less than $10 \mathrm{~m} \mathrm{~s}^{-1}$. In the present study, $75 \%$ of the WF events occurred when 4$6-\mathrm{km}$ SRW is less than $10.5 \mathrm{~m} \mathrm{~s}^{-1}$. There remains considerable overlap between SRW values of SF events and for those of tornadic supercells (Thompson 1998). However, since 11.5 tornadoes accompany each SF derecho on average, this may support the finding that SF derechos can exist in environments not supportive of enhanced cold pools.

The presence of shear somewhere in the lowest $6 \mathrm{~km}$ (as evidenced by the consistent differences between the low and midlevel SRW) increases the potential for storm-scale organization in our derecho cases. However, a comparison between WF derecho and nonderecho MCSs implies that it is the strength of the mean flow, and its possible effects on speed of movement, that enhances the development of sustained severe wind gusts at the surface, given similar thermodynamic environments. The importance of both the mean wind and downdraft potential within derecho environments is highlighted in Fig. 14, which reveals an inverse relationship between $0-6-\mathrm{km}$ mean flow and DCAPE. When mean wind and large-scale forcing are weak, the potential for strong downdrafts (cold pools) plays a dominant role in maintaining damaging surface winds. When the mean wind and large-scale forcing are strong, severe surface winds can occur with relatively weak downdrafts and cold pools.

It appears the environments simulated by Weisman (1992, 1993) may be only a subset of a larger range of the CAPE-shear parameter space we have found for observed derechos. Forecasters should be alert to the potential for derecho formation within environments of weaker shear than suggested by numerical simulations. This is especially true in the absence of a deep, progressive midtropospheric trough and an associated surface cold front. When synoptic-scale forcing is strong, derechos can develop and persist within environments of much less CAPE than implied by cloud model experiments and by JH87 and Johns et al. (1990).

Acknowledgments. The authors would like to extend a special thanks to Robert Johns of the Storm Prediction Center (SPC), who recognized the need for an observed sounding study and provided invaluable guidance through the project. Thanks are also extended to Stephen Corfidi of the SPC for providing the dates of the nonderecho MCSs and for his input during this study. We would also like to thank Steven Weiss of the SPC, as well as Dave Stensrud and Lou Wicker of the National Severe Storms Laboratory for their reviews and input on early versions of the manuscript. Many of the computations used in this work were accomplished with software developed by John Hart of the SPC. Thanks are also extended to the anonymous reviewers for their constructive criticism and subsequent improvements to the manuscript.

\section{REFERENCES}

Bentley, M. L., and T. L. Mote, 1998: A climatology of derechoproducing mesoscale convective systems in the central and eastern United States. Part I: Temporal and spatial distribution. Bull. Amer. Meteor. Soc., 79, 2527-2540.

Brooks, H. E., C. A. Doswell III, and J. Cooper, 1994a: On the environments of tornadic and nontornadic mesocyclones. Wea. Forecasting, 9, 606-618.

—_ _ — , and R. B. Wilhelmson, 1994b: The role of midtropospheric winds in the evolution and maintenance of low-level mesocyclones. Mon. Wea. Rev., 122, 126-136.

Browning, K. A., and F. H. Ludlam, 1962: Airflow in convective storms. Quart. J. Roy. Meteor. Soc., 88, 117-135.

Corfidi, S. F., 1998: Forecasting MCS mode and motion. Preprints 19th Conf. on Severe Local Storms, Minneapolis, MN, Amer. Meteor. Soc., 626-629.

Doswell, C. A., III, and E. N. Rasmussen, 1994: The effect of neglecting the virtual temperature correction on CAPE calculations. Wea. Forecasting, 9, 625-629.

Droegemeier, K. K., S. M. Lazarus, and R. Davies-Jones, 1993: The influence of helicity on numerically simulated convective storms. Mon. Wea. Rev., 121, 2005-2029.

Emanuel, K. A., 1994: Atmospheric Convection. Oxford University Press, $883 \mathrm{pp}$.

Fawbush, E. J., and R. C. Miller, 1954: A basis for forecasting peak wind gusts in nonfrontal thunderstorms. Bull. Amer. Meteor. Soc., 35, 14-19.

Foster, D. S., 1958: Thunderstorm gusts compared with computed downdraft speeds. Mon. Wea. Rev., 86, 91-94.

Fujita, T. T., 1978: Manual of downburst identification for project NIMROD. Satellite and Mesometeorology Res. Paper 156, Dept. of Geophysical Sciences, University of Chicago, 104 pp.

Garner, S. T., and A. J. Thorpe, 1992: The development of organized convection in a simplified squall-line model. Quart. J. Roy. Meteor. Soc., 118, 101-124.

Gilmore, M. S., and L. J. Wicker, 1998: The influence of midtropospheric dryness on supercell morphology and evolution. Mon. Wea. Rev., 126, 943-958.

Hamilton, R. E., 1970: Use of etailed intensity radar data in mesoscale surface analysis of the 4 July 1969 storm in Ohio. Preprints, 14th Conf. on Radar Meteorology, Tucson, AZ, Amer. Meter. Soc., 339-342.

Hinrichs, G., 1888: Tornadoes and derechos. Amer. Meteor. J., 5, 306-317, 341-349. 
Hookings, G. A., 1965: Precipitation-maintained downdrafts. J. Appl. Meteor., 4, 190-195.

Johns, R. H., 1993: Meteorological conditions associated with bow echo development in convective storms. Wea. Forecasting, 8, 294-299.

— duced windstorms. Wea. Forecasting, 2, 32-49.

- and C. A. Doswell III, 1992: Severe local storms forecasting. Wea. Forecasting, 7, 588-612.

_ K. W. Howard, and R. A. Maddox, 1990: Conditions associated with long-lived derechos- An examination of the large scale environments. Preprints, 16th Conf. on Severe Local Storms, Kananaskis Park, AB, Canada, Amer. Meteor. Soc., 408-412.

- J. M. Davies, and P. W. Leftwich, 1993: Some wind and instability parameters associated with strong and violent tornadoes. Part II: Variations in the combinations of wind and instability parameters. The Tornado: Its Structure, Dynamics, Hazards, and Prediction, Geophys. Monogr., No. 79, Amer. Geophys. Union, 583-590.

Nolen, R. H., 1959: A radar pattern associated with tornadoes. Bull. Amer. Meteor. Soc., 40, 277-279.

Orlanski, I., 1975: A rational sub-division of scales for atmospheric processes. Bull. Amer. Meteor. Soc., 56, 527-530.

Przybylinski, R. W., 1995: The bow echo: observations, numerical simulations, and severe weather detection methods. Wea. Forecasting, 10, 203-218.

- and W. J. Gery, 1983: The reliability of the bow echo as an important severe weather signature. Preprints, 13th Conf. on Severe Local Storms, Tulsa, OK, Amer. Meteor. Soc., 270-273.

- and D. M. DeCaire, 1985: Radar signatures associated with the derecho, a type of mesoscale convective system. Preprints, 14th
Conf. on Severe Local Storms, Indianapolis, IN, Amer. Meteor. Soc., 228-231.

Rasmussen, E. N., and R. B. Wilhelmson, 1983: Relationships between storm characteristics and 1200 GMT hodographs, low level shear, and stability. Preprints, 13th Conf. on Severe Local Storms, Tulsa, OK, Amer. Meteor. Soc., J5-J8.

Rotunno, R., J. B. Klemp, and M. L. Weisman, 1988: A theory for strong, long-lived squall lines. J. Atmos. Sci., 45, 463-485.

Schmidt, J. M., and W. R. Cotton, 1989: A high plains squall line associated with severe surface winds. J. Atmos. Sci., 46, 281301.

Stensrud, D. J., J. V. Cortinas Jr., and H. E. Brooks, 1997: Discriminating between tornadic and nontornadic thunderstorms using mesoscale model output. Wea. Forecasting, 12, 613-632.

Thompson, R. L., 1998: Eta Model storm-relative winds associated with tornadic and nontornadic supercells. Wea. Forecasting, 13, $125-137$.

Turcotte, V., and D. Vigneux, 1987: Severe thunderstorm and hail forecasting using derived parameters from standard RAOB data. Preprints, Second Workshop on Operational Meteorology, Halifax, NS, Canada, Atmospheric Environment Service/Canadian Meteorological and Oceanographical Society, 142-153.

Weisman, M. L., 1992: The role of convectively generated rear-inflow jets in the evolution of long-lived mesoscale convective systems. J. Atmos. Sci., 49, 1826-1847.

_ 1993: The genesis of severe, long-lived bow echoes. J. Atmos. Sci., 50, 646-670.

, and J. B. Klemp, 1986: Characteristics of isolated convective storms. Mesoscale Meteorology and Forecasting, P. Ray, Ed., Amer. Meteor. Soc., 331-358.

- — - and R. Rotunno, 1988: Structure and evolution of numerically simulated squall lines. J. Atmos. Sci., 45, 1900-2013. 